\title{
Impact of transition on public health in Ukraine: case study of the HIV/AIDS epidemic
}

\author{
Diane DeBell, Richard Carter
}

The link between HIV infection and human and economic development in Ukraine is a case study in the impact of economic transition on health

Centre for Research in Health and Social Care, Institute of Health and Social Care, Anglia Polytechnic University, Chelmsford CM1 1SQ Diane DeBell professor and director Every Child UK, London EC2A 3DR Richard Carter research manager Correspondence to: D DeBell ddebell@ compuserve.com
Ukraine has the highest per capita prevalence of HIV infection within Europe- $-1.4 \% .{ }^{12}$ This poses a serious threat to the region's social and economic stability. ${ }^{3}$ Ukraine is geographically the largest country in Europe, apart from the Russian Federation. Economic growth year on year started in 2000 , following a decade of recession during "transition" after the collapse of the Soviet Union (1989) and Ukrainian independence (1991). At current rates of growth, pre-transition levels of prosperity will not be reached until $2016 .{ }^{4}$

The impact of transition on public health is difficult to correlate precisely with socioeconomic and political change. The inability to manage the spread of HIV is one example of the way Ukraine's health system has been adversely affected by transition. HIV/AIDS is relatively new to the country, appearing in the mid-1990s, rising dramatically between 1995 and 2002, and continuing to rise at exponential rates (fig 1). The transmission route for infection was originally injecting drug use, mainly in young men, but infection is now spreading via unprotected heterosexual sex.

We investigate the link between HIV infection, now at epidemic levels, and human and economic development in Ukraine as a case study of the impact of transition on health.

\section{Health infrastructure}

Ukraine has no public health information service, no sexual health education in its schools, and no national information dissemination strategy for HIV/AIDS. At least a decade of corruption within the former Kuchma government has had a deleterious effect on development of public services, including the health system. ${ }^{6}$ Investment is mainly absorbed in maintaining large hospitals, a continuation of the pre-transition approach to health care. Communicable diseases carry a stigma within the population, and no public health

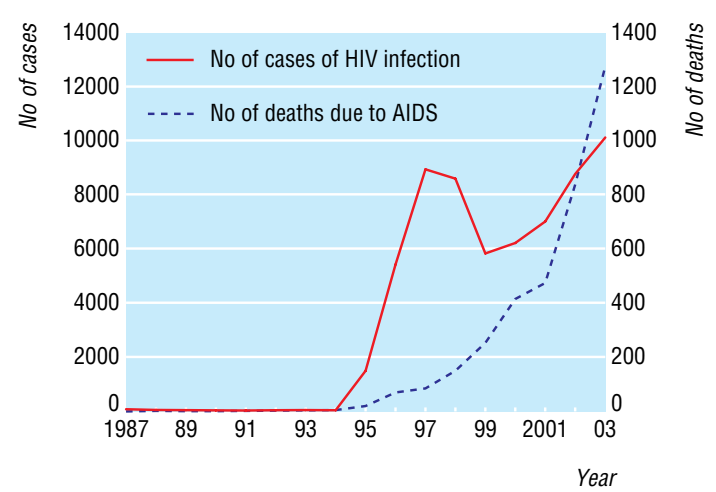

Fig 1 HIV/AIDS in Ukraine, 1987-2003

\section{The health system in Ukraine}

Before1989 the Soviet health system was based on a curative approach and provided services to the entire population. It was regarded as generally effective, as measured, for example, by reductions in infant mortality from the 1950 s and high immunisation rates. Now, barely a third of Ukraine's infants are vaccinated. Large reductions in expenditure on health care and in access to services followed economic transition and have seriously degraded the health system. Private purchase of health care exists alongside a state funded system. Ukraine is currently seeking international assistance to develop a system based on a combination of tax and insurance.

policy exists to fund HIV information, prevention, care, or treatment.

UNAIDS/WHO estimates that for the Eastern European and Central Asia region to avert continuous spread of infection and to treat those people who are already infected, funding should be scaled up from about $\$ 300 \mathrm{~m}$ to $\$ 1.5 \mathrm{bn}$ (from $£ 166 \mathrm{~m}$ to $£ 900 \mathrm{~m}$; $€ 250 \mathrm{~m}$ to $€ 750 \mathrm{~m}$ ) by 2007 , to reflect $2-3 \%$ of a national health budget. Of the region's funding, $60 \%$ is needed for Ukraine, Russia, and Kazakhstan.

Investment in healthcare services in Ukraine is generally inadequate, even when compared within the Eastern European and Central Asia region. The most recent available figures (for 2001) show 2.9\% of Ukraine's gross domestic product spent on public health care and $1.4 \%$ on private health care; the corresponding figures for the Russian Federation were 3.7\% and $1.7 \% .^{8}$

\section{Attitudes to prevention and treatment of AIDS}

Public awareness of HIV risk is low, a consequence of the government's neglect of public health. Lack of investment, widespread poverty, social and judicial constraints on decriminalisation of drug use, drug trafficking, and government corruption have been key influencing factors.

Cultural attitudes toward injecting drug users, sex workers, same sex relationships, immigrants, and people with communicable diseases remain punitive. At the same time, the country has experienced steep rises in injecting drug use, the initial transmission route for HIV. Corrupt border controls and drug trafficking have been internationally recognised features in Ukraine until recently. There is hope among the population that the new government under President Viktor Yushchenko, elected in December 2004, will change this profile. ${ }^{34}$ 
Education and debate

Injecting drug use remains criminalised, and the only treatment for addiction is via state mental health services or private psychosocial counselling services. No harm reduction programme is in place to help prevent HIV transmission.

Drug trafficking from the east, via the Black Sea, has produced an explosion in the numbers of intravenous drug users, and with it a spread in HIV, mainly in men, but infection is now rapidly moving into the heterosexual population. Our analysis of available data indicates that the River Dnieper is a permeable border: the five highest rates of intravenous drug users, in Dnipropetrovsk, Odesa, Kiev, Mikolaiv, and Zaporizhzhia, all lie along the Dnieper (fig 2, table 1). ${ }^{9}$ Targeting health care and treatment, information, and harm reduction programmes along this corridor would be a valuable first step.

The numbers of officially registered intravenous drug users inevitably under-report actual intravenous drug users (table 1). Because injecting drug users do not receive care or treatment, incentives to register are minimal, and actual numbers are higher than officially registered numbers.

\section{Poverty and wealth in Ukraine}

The gap between rich and poor is extreme, even for a transition economy-the World Bank estimates that average earnings are $\$ 4650$. The work force is well educated, yet labour costs are below $\$ 160$ a month per worker (labour costs in neighbouring Poland are $\$ 400$ a month). Low income is widespread despite national economic growth of at least $7.3 \%$ a year since 2000 . At the same time, a small minority of the population has capitalised on the transition to a private enterprise economy. Dollar multimillionaires control business and industry, the economy, the media, and parliament. This new system of oligarchy within Ukraine, combined with citizens' frustration at levels of corruption, was the primary focus for the strongly contested elections in 2004.

The government's total tax revenue is low because the population relies heavily on a cash economy. In 2004, Kuchma's government reduced the higher rate tax from $40 \%$ to an overall $13 \%$, thus favouring the wealthy. The government is not poor, but its revenue distribution has included no new investment for developing health care.

A combination of good macroeconomic policy from 2000 alongside a pattern of industrial ownership by a small number of private owners has produced a powerful group of wealthy Ukrainians. The consequence for health has been to create a wide gap between the seriously rich and the extremely poor. This favours private medicine at the expense of tax based or insurance based systems.

Poverty, the marginalisation of risk groups, and ignorance of the health implications of personal behaviour are the fuel that is ensuring spread of HIV. Furthermore, deaths from tuberculosis (which are also on the increase), hepatitis B and C, and causes of death associated with HIV are not necessarily registered as HIV/AIDS related where that is or may be the primary cause.
Table 1 Number of registered intravenous drug users per 100000 population in Ukraine

\begin{tabular}{|c|c|c|c|c|c|c|c|}
\hline Location & $\begin{array}{c}1996 \\
(n=51484)\end{array}$ & $\begin{array}{c}1997 \\
(n=54555)\end{array}$ & $\begin{array}{c}1998 \\
(n=61166)\end{array}$ & $\begin{array}{c}1999 \\
(n=62850)\end{array}$ & $\begin{array}{c}2000 \\
(n=68212)\end{array}$ & $\begin{array}{c}2001 \\
(n=73441)\end{array}$ & $\begin{array}{c}2002 \\
(n=76572)\end{array}$ \\
\hline Overall & 100.8 & 108.2 & 121.7 & 128.1 & 137.9 & 149.8 & 158.7 \\
\hline Cherkasy & 85.3 & 94.4 & 102.4 & 105.1 & 112.1 & 118.6 & 128.8 \\
\hline Chernivtsi & 27.2 & 32.0 & 38.7 & 42.5 & 49.5 & 56.76 & 69.3 \\
\hline Chernihiv & 80.0 & 91.3 & 105.4 & 118.2 & 130.2 & 146.5 & 160.7 \\
\hline Crimea & 113.1 & 126.0 & 128.0 & 119.6 & 128.3 & 142.5 & 160.4 \\
\hline Dnipropetrovsk & 334.6 & 310.5 & 338.4 & 357.6 & 384.3 & 413.1 & 417.1 \\
\hline Donetsk & 137.1 & 148.0 & 161.9 & 150.2 & 154.5 & 159.2 & 165.5 \\
\hline Ivano-Frankivsk & 31.6 & 33.0 & 39.6 & 48.1 & 54.3 & 57.1 & 63.9 \\
\hline Kharkiv & 44.9 & 47.6 & 50.7 & 49.4 & 50.5 & 53.1 & 53.1 \\
\hline Kherson & 89.0 & 92.1 & 111.7 & 120.7 & 138.1 & 149.3 & 166.2 \\
\hline Khmelnytskyi & 71.1 & 82.3 & 97.2 & 106.4 & 126.7 & 135.3 & 153.2 \\
\hline Kirovohrad & 59.3 & 73.4 & 85.0 & 99.3 & 133.1 & 162.9 & 196.6 \\
\hline Kyiv (Kiev) city & 77.6 & 104.2 & 135.9 & 163.8 & 200.0 & 238.4 & 276.6 \\
\hline $\begin{array}{c}\text { Kyiv (Kiev) } \\
\text { oblast }\end{array}$ & 49.5 & 47.6 & 52.1 & 63.3 & 70.7 & 77.6 & 83.9 \\
\hline Luhansk & 57.4 & 68.3 & 78.1 & 63.8 & 69.0 & 77.7 & 91.3 \\
\hline Lviv & 24.2 & 28.0 & 28.0 & 29.3 & 32.9 & 34.1 & 36.7 \\
\hline Mykolaiv & 249.8 & 265.0 & 303.4 & 323.4 & 303.2 & 282.4 & 234.3 \\
\hline Odesa & 202.9 & 217.2 & 256.1 & 268.7 & 296.8 & 311.4 & 328.1 \\
\hline Poltava & 69.9 & 89.0 & 96.8 & 113.7 & 124.4 & 150.8 & 166.5 \\
\hline Rivne & 39.7 & 47.3 & 50.9 & 56.9 & 69.8 & 85.6 & 96.4 \\
\hline Simferopil & 74.4 & 84.5 & 89.2 & 57.4 & 62.4 & 64.6 & 79.8 \\
\hline Sumy & 33.9 & 39.4 & 46.2 & 49.2 & 56.4 & 65.3 & 67.9 \\
\hline Ternopil & 19.6 & 22.3 & 24.5 & 26.4 & 27.5 & 27.5 & 30.7 \\
\hline Transcarpathia & 10.3 & 14.0 & 14.1 & 14.3 & 15.0 & 14.6 & 14.2 \\
\hline Vinnytsia & 23.4 & 28.0 & 33.7 & 39.4 & 44.9 & 54.3 & 60.6 \\
\hline Volyn & 79.4 & 94.2 & 108.5 & 121.9 & 140.0 & 151.0 & 163.8 \\
\hline Zaporizhzhia & 153.6 & 175.0 & 187.1 & 188.4 & 208.0 & 231.6 & 231.4 \\
\hline Zhytomyr & 43.5 & 46.1 & 52.9 & 67.3 & 85.1 & 98.0 & 112.3 \\
\hline
\end{tabular}

Source: UNAIDS/WHO. Ukraine. UNAIDS/WHO epidemiological fact sheets on HIV/AIDS and sexually transmitted infections, 2004 Update. Geneva: UNAIDS/WHO Working Group on Global HIV/AIDS and STI Surveillance, 2004

Surveillance, 2004.
Inconsistencies in the spelling of some place names arise from different conventions on transliteration from Russian and Ukrainian.

\section{Population targeting}

Just over half the population is in the 15-49 age group (the core workforce), with young adults (ages 15-29) in the highest HIV risk group. (The actual population figures are contested but evidence of progressive reduction in population numbers is widely accepted.) Epidemiological data are collected inside Ukraine without systematic cohort analysis. This has made it

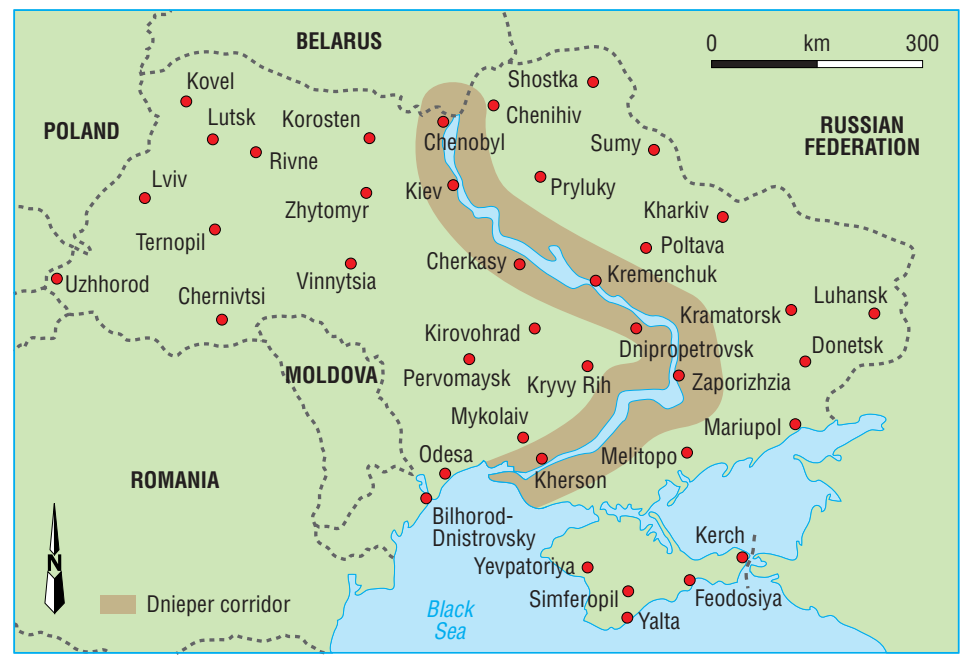

Fig 2 Ukraine's River Dneiper corridor has a high coincidence of drug use and HIV rates 
Table 2 Number of cases and deaths due to HIV/AIDS in Ukraine

\begin{tabular}{lccccccccccrrrrrrrr} 
& $\mathbf{1 9 8 7}$ & $\mathbf{1 9 8 8}$ & $\mathbf{1 9 8 9}$ & $\mathbf{1 9 9 0}$ & $\mathbf{1 9 9 1}$ & $\mathbf{1 9 9 2}$ & $\mathbf{1 9 9 3}$ & $\mathbf{1 9 9 4}$ & $\mathbf{1 9 9 5}$ & $\mathbf{1 9 9 6}$ & $\mathbf{1 9 9 7}$ & $\mathbf{1 9 9 8}$ & $\mathbf{1 9 9 9}$ & $\mathbf{2 0 0 0}$ & $\mathbf{2 0 0 1}$ & $\mathbf{2 0 0 2}$ & $\mathbf{2 0 0 3}$ & Total \\
\hline $\begin{array}{l}\text { No of cases of HIV } \\
\text { infection: }\end{array}$ & $\mathbf{8 1}$ & 55 & 48 & 40 & 34 & 45 & 51 & 44 & 1499 & 5422 & 8934 & 8590 & 5830 & 6216 & 7009 & 8761 & 10013 & 62672 \\
\hline Ukrainian citizens & 6 & 20 & 16 & 19 & 21 & 30 & 40 & 31 & 1490 & 5400 & 8913 & 8575 & 5827 & 6212 & 7000 & 8756 & 10009 & 62365 \\
\hline Foreign citizens & 75 & 35 & 32 & 21 & 13 & 15 & 11 & 13 & 9 & 22 & 21 & 15 & 3 & 4 & 9 & 5 & 4 & 307 \\
\hline Children & 0 & 4 & 2 & 3 & 4 & 2 & 1 & 0 & 12 & 99 & 210 & 402 & 549 & 737 & 937 & 1379 & 1844 & 6185 \\
\hline No of cases of AIDS: & 0 & 2 & 1 & 1 & 5 & 4 & 11 & 13 & 45 & 146 & 193 & 399 & 586 & 648 & 868 & 1356 & 196 & 6194 \\
\hline Ukrainian citizens & 0 & 2 & 1 & 1 & 4 & 4 & 10 & 10 & 45 & 143 & 189 & 398 & 586 & 647 & 867 & 1353 & 1915 & 6175 \\
\hline Foreign citizens & 0 & 0 & 0 & 0 & 1 & 0 & 1 & 3 & 0 & 3 & 4 & 1 & 0 & 1 & 1 & 3 & 1 & 19 \\
\hline Children & 0 & 1 & 1 & 0 & 2 & 0 & 1 & 1 & 1 & 10 & 4 & 14 & 15 & 13 & 30 & 47 & 68 & 208 \\
\hline No of deaths due to AIDS: & 0 & 2 & 1 & 1 & 2 & 3 & 4 & 5 & 20 & 70 & 85 & 150 & 253 & 415 & 474 & 837 & 1285 & 3607 \\
\hline Ukrainian citizens & 0 & 2 & 1 & 1 & 2 & 3 & 4 & 2 & 19 & 69 & 52 & 48 & 253 & 414 & 473 & 834 & 1285 & 3592 \\
\hline Foreign citizens & 0 & 0 & 0 & 0 & 0 & 0 & 0 & 3 & 1 & 1 & 3 & 2 & 0 & 1 & 1 & 3 & 0 & 15 \\
\hline Children & 0 & 1 & 1 & 0 & 2 & 0 & 0 & 0 & 1 & 6 & 4 & 9 & 12 & 9 & 11 & 23 & 38 & 117 \\
\hline
\end{tabular}

Source: Ukrainian Centre for Prevention and Treatment of AIDS, Ministry of Health of Ukraine

difficult to ascertain which sectors of the population to target in order to reduce HIV transmission rates.

The transmission of HIV and related infectious diseases threatens to deplete a generation of Ukrainian youth. In a country experiencing economic growth and considerable development potential, HIV/AIDS threatens to undermine the workforce, jeopardising a national resource on which the economy depends.

Largely because of the inadequacies of data collection, estimates of HIV infection and AIDS deaths vary considerably. Five years ago it was estimated that between 60000 and 180000 people were infected. ${ }^{10}$ The high estimate of deaths thus far from AIDS is $33000 .^{2}$ The rate of new infections is still rising, whereas in Russia, Estonia, and Moldova rates have declined since $2001 .^{2}$

Most data for surveillance of HIV/AIDS that include data from Ukraine are published outside the country. Evidence based on research within Ukraine is patchy and its quality varies between regions (oblasts). Despite sophisticated in-country expertise, the Ministry for Health has not used its in-country epidemiologists coherently.

\section{Summary points}

Ukraine has the highest per capita rate of HIV/AIDS infection in Europe, and this threatens the country's social and economic development

In Ukraine, HIV carries a severe social stigma, and public awareness of risk is low

Young people are at highest risk of new infection

The economic collapse that followed "transition" has left high levels of poverty and inequality and poor investment in the development of the country's health system

Ukraine needs a national strategy for HIV/AIDS information, prevention, care, and treatment and needs improved in-country surveillance data for population targeting
Cultural attitudes to infection, alongside the absence of population care and treatment programmes, are likely to be leading to under-reporting. Throughout the country, recorded infection rates increased by at least 13\% between 2001 and 2003. The number of deaths attributed to AIDS rose from 473 in 2001 to 3592 in 2003 (table 2)..$^{9}$

The exception to treatment patterns of no treatment is the provision of antiretroviral drugs for HIV infected pregnant women. UNAIDS/WHO reports that $91.3 \%$ of $1334 \mathrm{HIV}$ positive women who delivered in 2002 received antiretroviral prophylaxis of vertical transmission during pregnancy and delivery. This followed on from the maternal and child health services' programme for prevention of HIV infection in infants, which tested $97.5 \%$ of all pregnant women for HIV in 2002. No counselling is linked to HIV testing.

At present, parents tend to abandon infected babies to institutionalised state care. Reliable data are lacking for the numbers of children orphaned by HIV infected parents, but these numbers are likely to rise. Ukraine has no social care system to support vulnerable families, instead relying on large institutional "orphanages."

We thank Carol Munn-Giddings for commenting on an early draft, Richard Farr for technical assistance, and Jennie Hughes for research administration. A version of this paper was presented as a poster with supporting paper to the WHO Global Forum for Health Research Forum 8, 16-20 November 2004, Mexico City.

Contributors: DDB developed the initial focus and wrote the original draft. Both authors contributed to the writing and editing of the paper, analysed the field research, and carried out the literature search jointly. DDB is guarantor.

Funding: With Carol Munn-Giddings, DDB led a social research team in Ukraine from 2001 to 2003 funded by the UK Department for International Development Fund (Project UKR002). Every Child is an international non-governmental organisation funded mostly by public donations, but in part from the European Union and other large funding bodies. The views in this paper are entirely independent of funding bodies.

Competing interests: None declared.

1 AIDS Epidemic poses serious threat to stability in Europe, UNAIDS Press release, 16 September 2004. www.aegis.com/news/unaids/2004/ UN040902.html (accessed 7 Oct 2004).

2 UNAIDS. 2004 report on the global HIV/AIDS epidemic: 4th global report. www.unaids.org/bangkok2004/GAR2004_pdf/

UNAIDSGlobalReport2004 en.pdf (accessed 31 Jan 2005).

3 Bass E. Setting a scientific agenda for a house on fire: AIDS prevention research moves ahead in Russia. IAVI Report 2003;7(2). www.iavireport.org/ Issues/0803/Russia-main.asp (accessed 10 May 2005). 
4 World Bank. World development indicators database. New York: World Bank, 2004 Barnett T, Barr D, Ivanov A, Slay B. Reversing the epidemic: facts and policy. HIV/AIDS in Eastern Europe and the Commonwealth of Independent States. HIV/AIDS in Eastern Europe and the Commonwealth of Indep

6 Transparency International. Transparency International corruption perceptions index. Berlin: TI, 2004

7 Adeyi O, Chakraborty S, Ghys P, Mikkelsen H. Funding required for the response to HIV/AIDS in Eastern Europe and Central Asia. Mexico City: Futures Group and Instituto Nacional de Salud Publica, World Bank, UNAIDS Secretariat, 2003.
8 United Nations Development Programme. Human development report Unitet: Nulusat libery in (a) http://hdr.undp.org/reports/global/2004/pdf/hdr04_complete.pd accessed 23 June 2005)

9 Ukraine. UNAIDS/WHO epidemiological fact sheets on HIV/AIDS and sexually transmitted infections, 2004 update. www.who.int/GlobalAtlas/ PDFFactory/HIV/EFS_PDFs/EFS2004_UA.pdf (accessed 27 Aug 2004).

10 Barnett T, Whiteside A, Khodakevich L, Kruglov Y, Steshenko V. The HIV/AIDS epidemic in Ukraine: its potential social and economic impact. Soc Sci Med 2000;51: 1387-403.

\title{
Commentary: HIV is not just a transitional problem
}

\author{
Thomas E Novotny
}

The HIV and AIDS epidemic in eastern Europe and central Asia is changing. ${ }^{1-2}$ Despite data limitations, this region shows the fastest growth in HIV in the world. ${ }^{3}$ At the end of 2004, between 920000 and 2.1 million people in the region were living with HIV, compared with about 160000 in 1995. Most countries in the region have low level epidemics, with less than $1 \%$ prevalence among pregnant women and less than $5 \%$ prevalence among high risk groups. The countries most affected are Ukraine, Russia, and the Baltic states, but incidence is also increasing elsewhere. The driving force in most countries has been intravenous drug use, but other contributors include migration, commercial sex work, increasing rates of sexually transmitted infection, widening economic disparities, and multiple high risk behaviours among prison populations.

Rhodes and Simic describe in detail the risk environment that prevails in eastern Europe and the western Balkans. ${ }^{1}$ As national borders have been progressively opened, HIV risks have migrated across them along with people and goods, including illicit drugs. Civil society protections have not kept up with this globalisation, nor have legal frameworks that consider members of vulnerable groups as criminals or social deviants. But people with HIV infection are not deviants: they are predominantly young (more than $80 \%$ of new HIV cases occur in people younger than 30); they may be disenfranchised groups such as the Roma; they may be transport workers with sexually transmitted infection; and they are certainly heterosexual partners of intravenous drug users (the main bridge population).

DeBell and Carter (see p 216) describe how poverty and wealth disparities in Ukraine create fatalism and hopelessness about social risks and the exploding HIV epidemic. ${ }^{2}$ There is a critical lack of investment in health systems and in effective national strategies to control the spread of HIV. Corruption, trafficking, and stigma triangulate to isolate HIV outside the mainstream of health systems, thus assuring that official action will be slow.

\section{Global preventive opportunity}

HIV in eastern Europe and central Asia is now on the agenda for the international health community. The Global Fund to Fight AIDS, Tuberculosis, and Malaria; the World Bank; and European and other bilateral donors have given grants. ${ }^{4}$ It is rare that the international community has the opportunity to prevent an explosive problem, but that opportunity is at hand with HIV in eastern Europe. High level political commitment, attention to economic disparities, support for youth oriented programmes, programmes to reduce harm, and increased responsiveness of transitional health systems are all key components of HIV prevention. Without such bold actions, HIV will become an important and devastating long term problem for transitional health systems.

Competing interests: None declared.

\footnotetext{
1 Rhodes T, Simic M. Transition and the HIV risk environment. BMJ 2005;331:220-3.

DeBell D, Carter R. The impact of transition on public health in Ukraine: A case study of the HIV/AIDS epidemic. BMJ 2005;331:216-9.

3 UNAIDS/WHO. AIDS epidemic update: December 2004. www.unaids.org UNAIDS/WHO. AIDS epidenic

Chapter6_eastern_europe_centralasia_en.pdf.

4 Rosenmöller M, Novotny TE, Godinho J. HIV/AIDS at Europe's eastern edge: Economic and demographic challenges for health systems and disenfranchised populations. EUROHealth (in press).
}

Department of Epidemiology and Biostatistics, Institute for Global Health, University of California, San Francisco, CA, USA Thomas E Novotny director of international programmes tnovotny@ psg.ucsf.edu

\section{Randomised controlled trials for the $B M J$ need to be registered}

If you are the author of a randomised controlled trial that begins enrolment of patients after 1 July 2005 you must register it in a public trials registry, at or before the start of enrolment, for it to be considered for publication in the $B M J$. Trials that began patient enrolment on or before 1 July 2005 must be registered before 13 September 2005 to be considered for publication.

The $B M / \mathrm{s}$ criteria for a suitable public trials registry are that it is free to access, searchable, and identifies trials with a unique number; that registration is free or at minimal cost; that registered information is validated; that registered entry includes details to identify the trial and investigator and includes the status of the trial; and that the research question, methods, intervention, funding, and sponsorship must all be disclosed.

When you submit your paper to the $B M J$ please state the registration number of the trial and the name of the trials registry in the last line of your paper's structured abstract. 